\title{
A PEDAGOGIA VIVENCIAL HUMANESCENTE E A TEORIA DA APRENDIZAGEM SIGNIFICATIVA
}

Kisna Yasmin Andrade Alves¹, Viviane Euzébia Pereira Santos², Marta Silvânere Pereira Dantas³, Cláudia Cristiane Filgueira Martins ${ }^{4}$, Pétala Tuani Candido de Oliveira Salvador ${ }^{5}$, Yole Matias Silveira de Assis ${ }^{6}$

${ }^{1}$ Enfermeira. Doutoranda em Enfermagem. Universidade Federal do Rio Grande do Norte. Natal, RN, Brasil.

${ }^{2}$ Enfermeira. Doutora em Enfermagem. Docente do Departamento de Enfermagem da Universidade Federal do Rio Grande do Norte. Natal, RN, Brasil.

${ }^{3}$ Enfermeira. Discente da Especialização em Enfermagem do Trabalho. Universidade Federal do Rio Grande do Norte. Natal, $\mathrm{RN}$, Brasil.

${ }^{4}$ Enfermeira. Doutoranda em Enfermagem. Docente da Escola de Enfermagem da Universidade Federal do Rio Grande do Norte. Natal, RN, Brasil.

${ }^{5}$ Enfermeira. Doutoranda em Enfermagem. Docente da Escola de Enfermagem de Natal da Universidade Federal do Rio Grande do Norte. Natal, RN, Brasil.

${ }^{6}$ Enfermeira. Mestranda em Enfermagem. Universidade Federal do Rio Grande do Norte. Natal, RN, Brasil.

RESUMO: O estudo objetiva compreender a Pedagogia Vivencial Humanescente, como tecnologia para o ensino, à luz da Teoria da Aprendizagem Significativa. Trata-se de um ensaio teórico desenvolvido baseado em dois conceitos: a Pedagogia Vivencial Humanescente, que consiste em uma estratégia pedagógica inovadora para o ensino; e a Teoria da Aprendizagem Significativa de Ausubel, a qual diz respeito à interação cognitiva entre o novo conhecimento e as experiências prévias, de modo a fortalecer o educando como ser ativo na construção de seu saber. Conclui-se assim que a Pedagogia Vivencial Humanescente apresenta pressupostos coerentes com a Teoria do Aprendizado Significativo, compreendendo importante tecnologia para o ensino, além de contribuir com mudanças paradigmáticas no cenário da educação.

DESCRITORES: Enfermagem; Ensino; Aprendizagem.

\section{HUMANESCENT EXPERIENTIAL PEDAGOGY AND THE THEORY OF SIGNIFICANT LEARNING}

\section{LA PEDAGOGÍA VIVENCIAL Y LA TEORÍA DEL APRENDIZAJE SIGNIFICATIVO}

\begin{abstract}
The study aims to understand humanescent experiential pedagogy as a technology for teaching, according to the theory of significant learning. This is a theoretical essay, which is developed based on two concepts: humanescent experiential pedagogy, which consists of an innovative pedagogical strategy for teaching, and Ausubel's theory of meaningful learning, which concerns the cognitive interaction between new knowledge and prior experience, in order to strengthen the learner in how to be active in building their knowledge. It is therefore concluded that humanescent experiential pedagogy presents assumptions consistent with the theory of meaningful learning, comprising important technology for teaching, in addition to contributing to paradigm shifts in the education scenario. DESCRIPTORS: Nursing; Teaching; Learning.
\end{abstract}

RESUMO: El estudio tuvo la finalidad de comprender a Pedagogía Vivencial, como tecnología para la enseñanza, a la luz de la Teoría del Aprendizaje Significativo. Es un ensayo teórico desarrollado con base en dos conceptos: la Pedagogía Vivencial Hunanescente, que consiste en una estrategia pedagógica innovadora para la enseñanza; y la Teoría del Aprendizaje Significativo de Ausubel, la cual se asocía a la interacción cognitiva entre el nuevo conocimiento y las experiencias previas, de modo a fortalecer el educando como ser activo en la construcción de su saber. Se concluye que la Pedagogía Vivencial presenta presupuestos coherentes con la Teoría del Aprendizaje Significativo, comprendiendo importante tecnología para la enseñanza, además de contribuir con cambios paradigmáticos en el escenario de la educación.

DESCRITORES: Enfermería; Enseñanza; Aprendizaje. 


\section{INTRODUÇÃO}

O ensino da enfermagem no Brasil surge no séculoXIX em um momento em que se priorizavam as ações preventivas, voltada para a saúde pública, tendo em vista o caráter agroexportador do país na época. Posteriormente, surge um currículo voltado para as clínicas especializadas, de cunho curativo, permanecendo assim por um longo período no decorrer da história ${ }^{(1)}$. No entanto, hoje, o que se almeja é a formação de profissionais de forma generalista, humanista, crítica, reflexiva, guiados pelos aspectos científicos e éticos, e capazes de desenvolver atividades em saúde voltadas para o novo paradigma de produção social da saúde(2).

Para a concretização de tais aspectos, é fundamental a utilização de tecnologias inovadoras para o ensino. A tecnologia para o ensino na enfermagem, e em demais áreas profissionais, não é vislumbrada como apenas maquinários sofisticados, mas como toda a complexidade intrínseca ao conhecimento e relações humanas que compõem o processo de ensino-aprendizagem.

Dessa forma, entende-se que a tecnologia auxilia no desenvolvimento da competência, na eficiência humana às diversas atividades, a partir de um conjunto de conhecimentos científicos e empíricos, apresentados de forma sistematizada e especializada, que desencadeiam o raciocínio teórico e prático ${ }^{(3)}$.

No âmbito do ensino, busca-se a educação voltada para a valorização das emoções na relação educador-educando, aspirando a estimular toda a criatividade inerente a cada ser, em detrimento do autoritarismo e da relação de subordinação existente no processo de ensino-aprendizagem, iniciada no passado e que, por vezes, permanece até os dias atuais ${ }^{(4)}$.

Urge, na atualidade, a necessidade contínua de educadores capazes de transformar a prática pedagógica em momento de prazer e satisfação tanto para o educador como para o educando a fim de tornar o processo educativo mais eficaz.

Com isso, a Pedagogia Vivencial Humanescente $(\mathrm{PVH})$ busca proporcionar aprendizagem significativa para o educando, estimulando todo o seu conhecimento prévio, abolindo a transmissão do conhecimento de forma unidirecional, estimulando dessa forma a sua capacidade crítica e reflexiva ${ }^{(5)}$.

Dessa maneira, por meio da Teoria da
Aprendizagem Significativa, busca-se construir um processo educativo alicerçado nos saberes prévios dos educandos, tendo por objetivo tornar o processo educativo mais dinâmico, em que por meio de atividades de ensino bem planejadas, os alunos aprofundem, ampliem e modifiquem seus conhecimentos $^{(6)}$.

Ausubel, considerado um dos principais autores, senão o principal, da aprendizagem significativa, tem sua teoria baseada na reflexão sobre a aprendizagem escolar, o ensino e a forma de absorção dos conteúdos pelos alunos. Ele defende que a eficácia da aprendizagem significativa está relacionada à maneira de aquisição de novos significados ${ }^{(7)}$.

Tendo em vista a interdependência entre a PVH e a Teoria da Aprendizagem Significativa e a necessidade de ampliar as discussões acerca de modalidades tecnológicas inovadoras para o processo de ensino-aprendizagem, questionase: como se caracteriza a $\mathrm{PVH}$, como tecnologia para o ensino à luz da Teoria de Aprendizagem Significativa?

Assim, o estudo objetiva refletir sobre a PVH como tecnologia para o ensino, à luz da Teoria de Aprendizagem Significativa.

\section{REFERENCIAL TEÓRICO, CONCEITUAL E O CAMINHO METODOLÓGICO}

Trata-se de um ensaio teórico desenvolvido a partir dos referenciais teóricos e conceituais da Pedagogia Vivencial Humanescente e a Teoria da Aprendizagem Significativa de Ausubel.

A PVH corresponde a uma estratégia pedagógica e uma tecnologia para o ensino inovadora, que incentiva o ensino do aprender a ser, bem como traz reflexões sobre a forma de ensinar, relacionar com o ser educativo e consolidar a humanescência - termo utilizado para o renascimento das essências humanas ${ }^{(8)}$. Essa concepção desenvolve a interface entre a educação aos fatores quânticos, trazendo uma concepção voltada para um campo de vibração quântica e, consequentemente, uma intervenção pedagógica transcorporal e humanescente ${ }^{(9)}$.

A Teoria da Aprendizagem Significativa de Ausubel caracteriza-se pela interação cognitiva entre o novo conhecimento e as experiências prévias, fortalecendo o educando como agente ativo da construção de seu saber. Para esse processo, adquirir estabilidade dos significados é fundamental ${ }^{(10-11)}$. 
Inserida nessa modalidade, destaca-se a Aprendizagem Significativa Crítica que possibilita o sujeito a fazer parte de sua cultura e, simultaneamente, ser exterior a ela. Ou seja, é uma perspectiva antropológica de atividades com grupos sociais, em que a aprendizagem trabalha, construtivamente, com a não causalidade, a relatividade, a probabilidade, a não dicotomização das diferenças e com a assertiva de que o conhecimento é construção nossa ${ }^{(12)}$.

A Aprendizagem Significativa Crítica apresenta onze princípios medulares: 1) Princípio do conhecimento prévio; 2) Princípio da interação social e do questionamento; 3) Princípio da não centralidade do livro de texto; 4) Princípio do aprendiz como perceptor/representador; 5) Princípio do conhecimento como linguagem; 6) Princípio da consciência semântica; 7) Princípio da aprendizagem pelo erro; 8) Princípio da desaprendizagem; 9) Princípio da incerteza do conhecimento; 10) Princípio da não utilização do quadro de giz; e 11) Princípio do abandono da narrativa $^{(12)}$ (Figura 1).

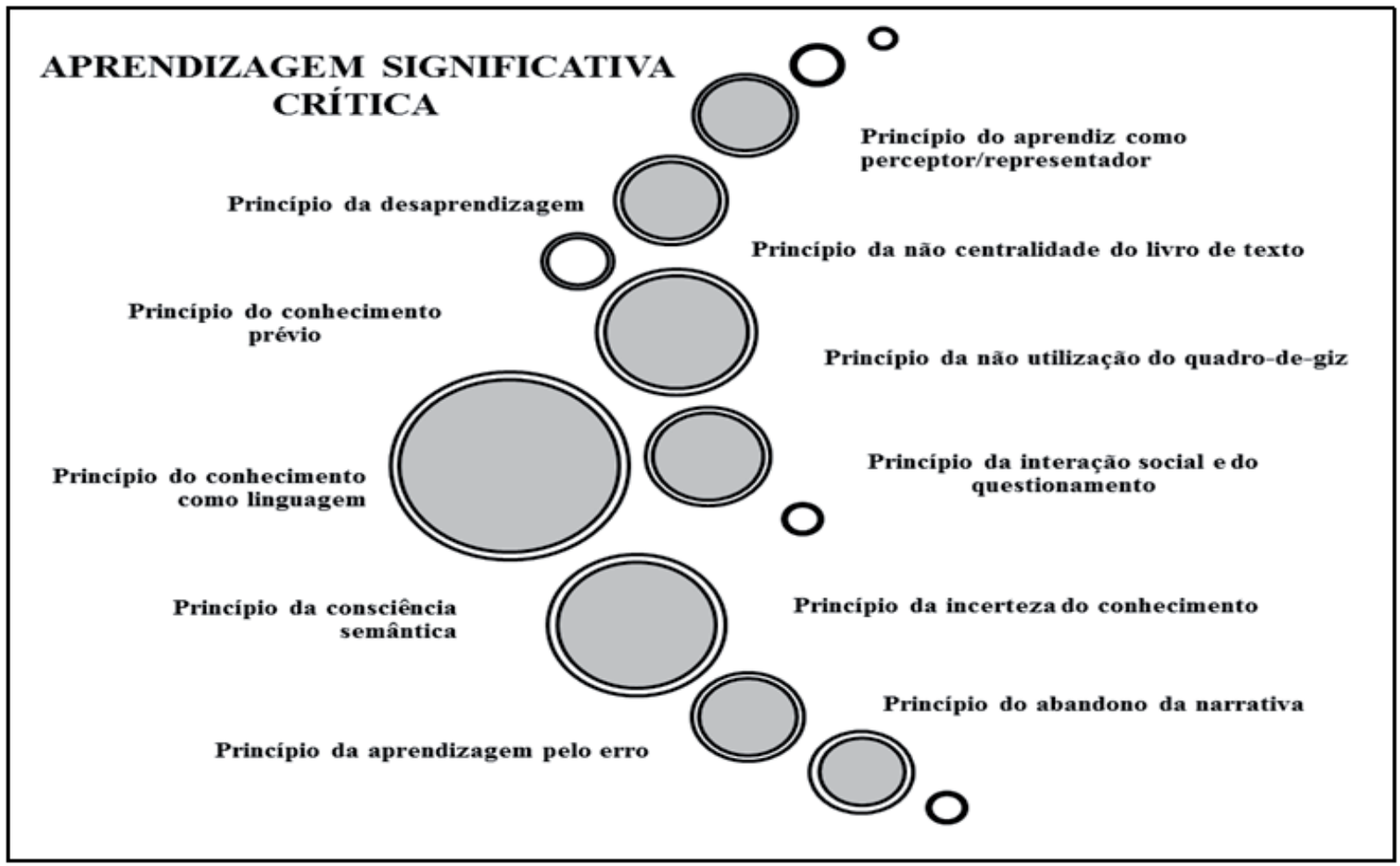

Figura 1 - Princípios da Aprendizagem Significativa Crítica. Brasil,2014.

De tal modo, como fonte teórica para as reflexões acerca das temáticas, utilizou-se a coletânea de trabalhos produzidos a partir dos pressupostos da $\mathrm{PVH}$, apresentada na obra intitulada "Pedagogia Vivencial Humanescente: para sentir-pensar os sete saberes na educação" (13) e as produções científicas do Dr. Marco Antônio Moreira, pesquisador renomado na área de teorias de aprendizagem, especialmente a da Aprendizagem Significativa. As reflexões serão apresentadas no pilar teórico: A PVH e a Aprendizagem Significativa Crítica.

\section{A PVH E A APRENDIZAGEM SIGNIFICATIVA CRÍTICA}

A PVH apresenta os princípios da ludicidade, sensibilidade, criatividade e reflexividade como norteadores pedagógicos. Contudo, para vivenciálos é necessário desenvolver algumas fases experienciais, que possibilitam um aprendizado significativo $^{(5)}$ (Figura 2).

A primeira fase, "imaginar ou resgatar experiências prévias", corresponde ao momento onde o ser educando é motivado a vivenciar a "refletividade histórica", ou seja, é levado a pensar, imaginar e resgatar algo relacionado à temática em pauta que, de modo geral, constitui os saberes ou experiências prévias.Ao vivenciar a fase de "expressar o imaginário através de uma técnica projetiva", por sua vez, o educando atua como protagonista do seu processo de ensinoaprendizagem,através da projeção simbólica da imaginação e pensamento. Trata-se de um momento de subjetividade humana e de experiência de associações dicotômicas como: razão e emoção, consciente e inconsciente, indivíduo e sociedade, e interno e externo ${ }^{(5)}$.

À luz da teoria de aprendizagem significativa 


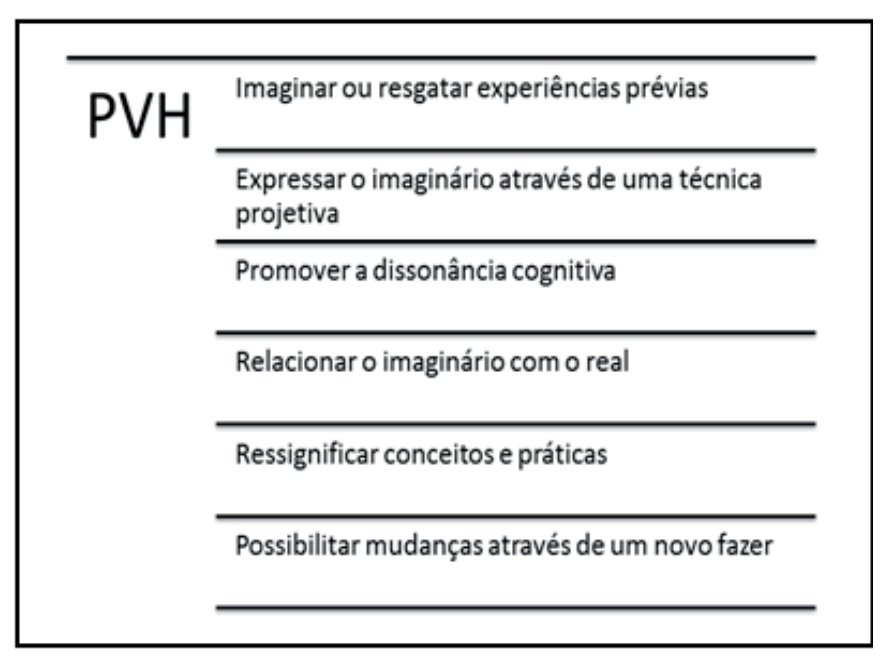

Figura 2-Etapas da Pedagogia Vivencial Humanescente. Brasil, 2014.

crítica, observa-se, peloprincípiodoconhecimento prévio, que só se aprende a partir do que já sabe, de forma não arbitrária, mediante captação e internalização dos significados construídos socialmente e contextualmente aceitos. Pode-se afirmar, portanto, que o conhecimento prévio é a variável mais importante do processo ${ }^{(11)}$.

As fases da PVH "promover dissonância cognitiva" e "relacionar o imaginário com o real" possibilitam conflitos e discordâncias e, a partir disso, a ressignificação do conhecimento. Posteriormente a esse momento, o educando interage com o contexto, discute e compara as concepções teóricas apresentadas no grupo. Nesse momento, é possível "sentir-pensar" a "refletividade vivencial"(5).

A interação social é imprescindível para a consolidação do processo de ensino, em especial, entre o binômio educador-educando que partilham significados. Assim, atenta-se para a consolidação da postura dialógica, curiosa, indagadora, aberta e não passiva do binômio(11).

Os momentos de "ressignificar conceitos e práticas" e "possibilitar mudanças através de um novo fazer" são caracterizado pela reformulação de um novo pensamento, corporalização de novas práticas e, consequentemente, surgimentos de novos sentimentos e atitudes ${ }^{(5)}$. Esses aspectos reforçam a importância do conhecimento prévio, já que o novo conhecimento ancora-se nele e possibilita identificar o que é necessário para efetivar o princípio da desaprendizagem, ou seja,"aprender a desaprender, a não usar conceitos e estratégias irrelevantes para a sobrevivência" (11:20), como mostra a Figura 3.

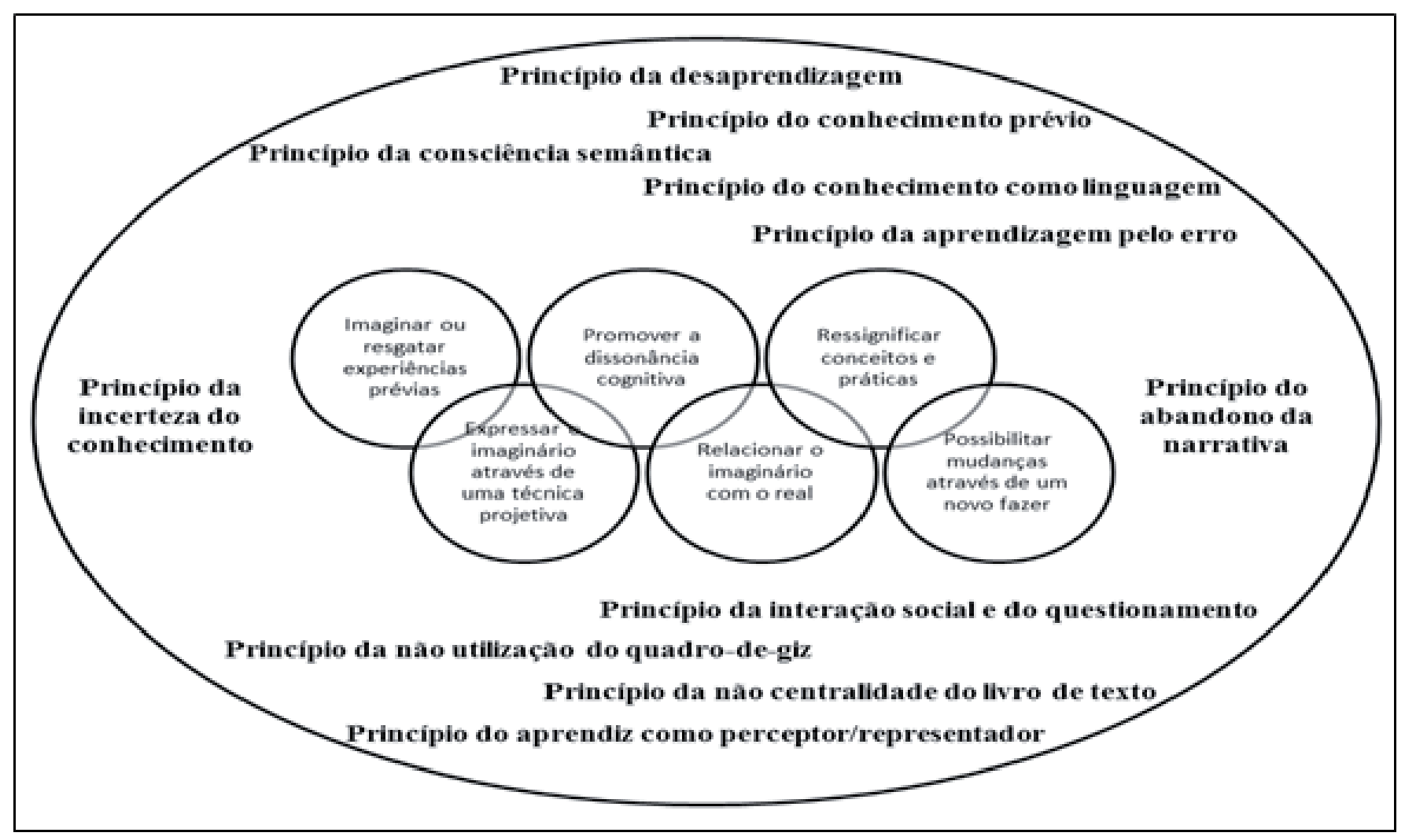

Figura 3 - Interfaces da PVH e a Aprendizagem Significativa Crítica. Brasil, 2014. 
A PVH destaca o aprender através de perguntas e não respostas, a partir de distintos materiais e estratégias didáticas, enfatiza que os educandos são perceptores e representante do mundo e que o significado é inerente às pessoas e não às palavras. Esses aspectos estão em consistência com os princípios da não centralidade do livro de texto, da não utilização do quadro de giz, do aprendiz como perceptor/representador e da consciência semântica ${ }^{(11)}$.

Realça-se, por fim, que essa inovação pedagógica utiliza como estratégia para associar a educação à vida dos sujeitos o "sentir-pensar"(5), uma forma de vivenciar emotiva e racionalmente o processo de ensino-aprendizagem. A estruturação teórica e a prática da PVH possibilita que o ensino centralize-se no educando, ressaltando o Princípio do abandono da narrativa. Consequentemente, esse sujeito fala mais e o educador menos ${ }^{(11)}$.

A Figura 3 representa, de forma sintetizada, as interfaces da PVH e a Aprendizagem Significativa Crítica.

\section{CONSIDERAÇÕES FINAIS}

Observa-se que a PVH apresenta pressupostos coerentes com a Teoria do Aprendizado Significativo Crítico, possibilitando um processo de construção de conhecimentos pautado nas vivências dos sujeitos e em metodologia não conservadora, com o norte na autonomia do educando.

Assim, o aluno desenvolve sua capacidade crítica e reflexiva, atuando como coautor em seu processo de ensino-aprendizagem; estabelece-se então uma relação harmoniosa entre educador e educando, capaz de tornar o processo de ensinoaprendizagem mais prazeroso e eficaz.

Observa-se, desse modo, a aliança entre tecnologia e o ensino no intuito de proporcionar aos educandos uma aprendizagem significativa e aos educadores uma mudança nos paradigmas profissionais direcionada às novas tendências.

Destarte, a PVH passa a representar não somente uma tecnologia para o ensino, mas uma estratégia de mudanças paradigmáticas no ensino. Diante dessa constatação, questiona-se: como a PVH contribui para as mudanças paradigmáticas no ensino? Esse questionamento demanda novas reflexões, instigando os autores à construção futura de novos estudos para sanar essa lacuna de conhecimento.

\section{REFERÊNCIAS}

1. Germano RM. Educação e ideologia da enfermagem no Brasil (1955-1980). 4ªed. São Paulo: Yendis; 2007.

2. Conselho Nacional de Educação. Resolução CNE/ $\mathrm{CES} \mathrm{N}^{\circ}$ 3, de 7 de novembro de 2001. Institui Diretrizes Curriculares Nacionais do Curso de Graduação em Enfermagem. [Internet] 2001 [acesso em 23 Fev 2013]. Disponível: http://portal.mec.gov.br/cne/arquivos/pdf/ CES03.pdf

3. Koerich MS, Backes DS, Scortegagna HM, Wall ML, Veronese AM, Zeferino MT. Tecnologias de cuidado em saúde e enfermagem e suas perspectivas filosóficas. TextoContexto Enferm. [Internet] 2006; 15(esp):17885 [acesso em 23 fev 2013]. Disponível:http://dx.doi. org/10.1590/S0104-07072006000500022

4. Ribeiro ML. A afetividade na relação educativa. Estud.Psicol. [Internet] 2010; 27(3):403-412 [acesso em 23 fev 2013]. Disponível: http://dx.doi.org/10.1590/ S0103-166X2010000300012

5. Sampaio, ATL. Pedagogia Vivencial Humanescente: complexidade e transdisciplinaridade para reencantar a educação. In: Conferência Internacional sobre os Sete Saberes; 2010 Set. Fortaleza, Brasil. Fortaleza: Editora da Universidade Estadual do Ceará; 2010.

6. Valadares J. A teoria da aprendizagem significativa como teoria construtivista. Aprendizagem significativa em revista. [internet] 2011; 1(1): 36-57 [acesso em $23 \mathrm{fev}$ 2013]. Disponível: http://www.if.ufrgs.br/asr/artigos/ Artigo_ID4/v1_n1_a2011.pdf

7. Ausubel, DP. Aquisição e retenção de conhecimentos: uma perspectiva cognitiva. $1^{\mathrm{a}}$ ed. Lisboa: Plátano Edições Técnicas; 2003.

8. Sampaio ATL. Pedagogia Vivencial Humanescente: educação para sentirpensar a condição humana. In: Cavalcanti KB, organizadora. Pedagogia Vivencial Humanescente: para sentirpensar os sete saberes na educação. Curitiba: Editora CRV; 2010. p. 29-44.

9. Cavalcanti KB. Corporiedade e a ética do sentido de vida na educação: para florescer as sementes da pedagogia vivencial. Revista Internacional de Creatividad Aplicada Total. [Internet], 2007; 7(2) [acesso em 23 fev 2013]. Disponível: http://www.iacat.com/ revista/recrearte/recrearte07/Seccion2/corporeidade. html

10. Gomes AP, Dias-Coelho UC, Cavalheiro PO, Gonçalves CAN, Rôças G, Siqueira-Batista R.A Educação Médica entre mapas e âncoras: a aprendizagem significativa de David Ausubel, em busca da Arca Perdida. Rev. bras. educ. med. [Internet] 2008, 32(1) [acesso em 23 fev 2013]. Disponível: http:// dx.doi.org/10.1590/S0100-55022008000100014 
11. Moreira MA, Caballero MC, Rodríguez ML (orgs.). Actas del Encuentro Internacional sobre el Aprendizaje Significativo. Burgos, España; 1997. p. 19-44.

12. Moreira MA. Aprendizaje significativo crítico. Indivisa, Bol. Estud. Invest. 2005, 6: 83-101.

13. Cavalcanti KB, organizadora. Pedagogia Vivencial Humanescente: para sentirpensar os sete saberes na educação. Curitiba: Editora CRV; 2010. 